\title{
PENGARUH KOMUNIKASI, MOTIVASI, DISIPLIN KERJA TERHADAP KINERJA KARYAWAN CV. DENOV PUTRA BRILIAN TULUNGAGUNG
}

\author{
Zulfana Khongida, Nining Purnamaningsih, Daniel \\ Universitas Kadiri - Kota Kediri
}

\begin{abstract}
The purpose of this study is (1) To determine the effect of variable communication on employee performance in CV. Denov Son Of The Brilliant Tulungagung. (2) To determine the influence of motivation variables on employee performance in $C V$. Denov Son Of The Brilliant Tulungagung. (3) To determine the effect of the variable of work discipline on employee performance in CV. Denov Son Of The Brilliant Tulungagung. (4) To determine the effect of variable communication, motivation, and work discipline simultaneously on employee performance in $C V$. Denov Son Of The Brilliant Tulungagung.This study uses a quantitative approach. The sampling method using the sampling method saturated. The sample in this study amounted to 63 respondents. Methods of data collection using questionnaires, interviews, and literature study. Data analysis method used is multiple linear regression. Based on the results of the research can be concluded that (1) Communication has positive and significant effect on employee performance with the results of the t test count 2,130 with significance level 0,037<0,05. (2) Motivation has positive and significant effect on employee performance with the results of the test count 4,469 with significance level of 0,000<0,05. (3) the employee's Performance has positive and significant effect on employee performance with the results of the t test count 2.935 per with the level of significance 0,005<0,05. (4) Communication, motivation, and work discipline simultaneously influence on the performance of employees with the results of the test $F$ count 68,848 with a significance level of 0,000<0,05.
\end{abstract}

Keywords : Communication, Motivation, Work Discipline, Employee Performance.

\begin{abstract}
ABSTRAK
Tujuan penelitian ini adalah (1) Untuk mengetahui pengaruh variabel komunikasi terhadap kinerja karyawan di CV. Denov Putra Brilian Tulungagung. (2) Untuk mengetahui pengaruh variabel motivasi terhadap kinerja karyawan di CV. Denov Putra Brilian Tulungagung. (3) Untuk mengetahui pengaruh variabel disiplin kerja terhadap kinerja karyawan di CV. Denov Putra Brilian Tulungagung. (4) Untuk mengetahui pengaruh variabel komunikasi, motivasi, dan disiplin kerja secara simultan terhadap kinerja karyawan di CV. Denov Putra Brilian Tulungagung.Penelitian ini menggunakan pendekatan kuantitatif. Metode pengambilan sampel menggunakan metode sampling jenuh. Sampel dalam penelitian ini berjumlah 63 responden. Metode pengumpulan data menggunakan kuisioner, wawancara, dan studi pustaka. Metode analisis data yang digunakan adalah regresi linier berganda. Berdasarkan hasil penelitian dapat disimpulkan bahwa (1) Komunikasi berpengaruh positif dan signifikan terhadap kinerja karyawan dengan hasil uji t hitung 2,130 dengan taraf signifikasi 0,037<0,05. (2) Motivasi berpengaruh positif dan signifikan terhadap kinerja karyawan dengan hasil uji t hitung 4,469 dengan taraf signifikasi $0,000<0,05$. (3) Kinerja karyawan berpengaruh positif dan signifikan terhadap kinerja karyawan dengan hasil uji t hitung 2,935 dengan
\end{abstract}


taraf signifikasi $0,005<0,05$. (4) Komunikasi, motivasi, dan disiplin kerja berpengaruh secara simultan terhadap kinerja karyawan dengan hasil uji $\mathrm{F}$ hitung 68,848dengan taraf signifikasi $0,000<0,05$.

Kata Kunci: Komunikasi, Motivasi, Disiplin Kerja, Kinerja Karyawan

\section{PENDAHULUAN}

Di era globalisasi seperti saat ini menjadikan persaingan semakin tinggi didalam dunia bisnis, perusahaan berusaha untuk dapat mempertahankan keberadaannya didalam persaingan bebas (Indriyani, 2016).Karyawan merupakan asset yang sangat berharga bagi perusahaan. Jika tidak ada peran dari karyawan meskipun perusahaan memiliki alat-alat yang canggih, tujuan perusahaan tidak akan tercapai.

Untuk menggerakan bagian-bagian yang ada di organisasi, manusia harus berinteraksi sosial sehingga terbentuk kerjasama. Dalam komunikasi, berbagai hal yang menyangkut kehidupan organisasi disampaikan oleh satu pihak ke pihak lain (Siagian, 2008). Dengan adanya komunikasi yang baik didalam organisasi, maka kerjasama diorganisasi juga akan baik. Kenyamanan dalam bekerja akan timbul apabila komunikasi terjalin dengan baik (Armhy, 2014).

Seorang pimpinan harus berupaya agar karyawan mempunyai motivasi tinggi dalam bekerja, karena motivasi kerja dapat mendorong karyawan menjadi semangat bekerja dan memberikan yang dimilikinya seperti kemampuandan ketrampilan karyawan untuk mencapai tujuan perusahaan. (Martinus, 2016). Prestasi kerja akan rendah jika karyawan tidak mempunyai motivasi untuk melakukan pekerjaan begitu juga sebaliknya(Satriyono, 2017), maka dari itu motivasi dan kinerja saling berkaitan (Harlie, 2010). Ketika karyawan mendapatkaninsentif, pengakuan, dan penghargaan, maka motivasi karyawan juga akan meningkat Danish dan Ali (2010).

Salah satu faktor yang mempengaruhi kinerja karyawan yakni disiplin kerja (Turangan et al.2016). Pekerjaan akan dapat dilakukan secara maksimal dengan adanya disiplin kerja. Seseorang yang disiplin kerja cenderung akan bekerja sesuai dengan peraturan dan kewajiban. Jadi setidaknya dapat meminimalisasi pelanggaran peraturan perusahaan.

\section{Rumusan Masalah}

Permasalahan dari perusahaan ini adalah rendahnya kinerja karyawan, maka peneliti merumuskan masalah sebagai berikut: 
1. Apakah komunikasi berpengaruh positif terhadap kinerja karyawan di CV. Denov Putra Brilian Tulungagung?

2. Apakah motivasi berpengaruh positif terhadap kinerja karyawan di CV. Denov Putra Brilian Tulungagung?

3. Apakah disiplin kerja berpengaruh positif terhadap kinerja karyawan di CV. Denov Putra Brilian Tulungagung?

4. Apakah variabel komunikasi, motivasi, dan disiplin kerja berpengaruh simultan terhadap kinerja karyawan CV. Denov Putra Brilian Tulungagung?

\section{Tujuan Penelitian}

Berdasarkan latar belakang dan rumusan masalah di atas, maka penelitian ini dilakukan dengan tujuan:

1. Untuk mengetahui pengaruh variabel komunikasi terhadap kinerja karyawan di CV. Denov Putra Brilian Tulungagung.

2. Untuk mengetahui pengaruh variabel motivasi terhadap kinerja karyawan di CV. Denov Putra Brilian Tulungagung.

3. Untuk mengetahui pengaruh variabel disiplin kerja terhadap kinerja karyawan di CV. Denov Putra Brilian Tulungagung

4. Untuk mengetahui pengaruh variabel komunikasi, motivasi, dan disiplin kerja secara simultan terhadap kinerja karyawan di CV. Denov Putra Brilian Tulungagung

\section{TINJAUAN PUSTAKA}

\section{Penelitian Terdahulu}

Tabel 1 : Penelitian Terdahulu

\begin{tabular}{|c|c|c|c|c|}
\hline No & Nama Peneliti & Judul & $\begin{array}{c}\text { Variabel dan Alat } \\
\text { Analisis }\end{array}$ & Hasil Penelitian \\
\hline 1 & $\begin{array}{l}\text { Windy Dyah } \\
\text { Indryani dan } \\
\text { Anindita } \\
\text { Budiarti (2016) }\end{array}$ & $\begin{array}{l}\text { Pengaruh Gaya } \\
\text { Kepemimpinan, } \\
\text { Motivasi dan Disiplin } \\
\text { Kerja Terhadap Kinerja } \\
\text { Karyawan (PT Karya } \\
\text { Indah Buana Surabaya) }\end{array}$ & $\begin{array}{l}\text { Jenis Penelitian: } \\
\text { Kuantitatif } \\
\text { Variabel: } \\
\text { 1. Gaya } \\
\text { Kepemimpinan } \\
\text { 2. Motivasi } \\
\text { 3. Disiplin Kerja } \\
\text { 4. Kinerja } \\
\text { Karyawan } \\
\text { Analisis Data: } \\
\text { Regresi Linear } \\
\text { Berganda }\end{array}$ & $\begin{array}{l}\text { Variabel } \\
\text { Kepemimpinan, Motivasi, } \\
\text { Disiplin Kerja memiliki } \\
\text { pengaruh yang signifikan } \\
\text { baik secara simultan } \\
\text { maupun parsial terhadap } \\
\text { kinerja karyawan dan } \\
\text { variabel yang berpengaruh } \\
\text { dominan adalah variabel } \\
\text { motivasi dengan nilai } \\
\text { sebesar 87,42\% }\end{array}$ \\
\hline
\end{tabular}




\begin{tabular}{|c|c|c|c|c|}
\hline 2 & $\begin{array}{l}\text { Agung } \\
\text { Karismadiyanto } \\
\text { (2014) }\end{array}$ & $\begin{array}{l}\text { Analisis Pengaruh } \\
\text { Motivasi Kerja, Disiplin } \\
\text { Kerja dan Komunikasi } \\
\text { Terhadap Kinerja } \\
\text { Karyawan (Koperasi } \\
\text { Arta Niaga } \\
\text { Banyuwangi) }\end{array}$ & $\begin{array}{l}\text { Jenis Penelitian: } \\
\text { Kuantitatif } \\
\text { Variabel: } \\
\text { 1. Motivasi Kerja } \\
\text { 2. Disiplin Kerja } \\
\text { 3. Komunikasi } \\
\text { 4. Kinerja } \\
\text { Karyawan } \\
\text { Analisis Data: } \\
\text { Regresi Linear } \\
\text { Berganda }\end{array}$ & \begin{tabular}{lr}
\multicolumn{3}{l}{ Variabel motivasi, disiplin, } \\
komunikasi memiliki \\
pengaruh yang signifikan \\
baik secara simultan \\
maupun parsial terhadap \\
kinerja karyawan Koperasi \\
Arta Niaga Banyuwangi.
\end{tabular} \\
\hline
\end{tabular}

Sumber: Indryani dan Budiarti (2016), Karismadiyanto (2014)

\section{Landasan Teori}

\section{Manajemen Sumber Daya Manusia}

Manajemen sumber daya manusia adalah ilmu dan seni yang mengatur hubungan dan peranan tenaga kerja agar efektif dan efesien dalam penggunaan kemampuan manusia agar dapat mencapai tujuan di setiap perusahaan (Hasibuan 2012).Menurut Cushway (2002), Manajemen sumber daya manusia yakni bagian dari proses organisasi dalam mencapai tujuan.

\section{Komunikasi}

Paripurna (2012),menyatakan bahwa komunikasi merupakan proses penyampaian pesan atau maksud yang dilakukan melalui satu pihak kepada pihak lain baik dilakukan secara langsung atau melalui media. Di dalam suatu organisasi ternyata komunikasi sangat memegang peranan penting, karena komunikasi adalah alat yang digunakan oleh semua pihak. Tinggal bagaimana suatu pihak mempergunakan dengan tepat, jika komunikasi yang disampaikan tidak tepat maka akan terjadi kesalahpahaman antara pemberi dan penerima pesan.

\section{Motivasi}

Hasibuan (2007:141) mengatakan bahwa motivasi berasal dari kata latin "movere" yang berarti "dorongan atau daya penggerak".Motivasi mempersoalkan bagaimana caranya mengarahkan daya dan potensi bawahan, agar mau bekerja sama secara produktif berhasil mencapai dan mewujudkan tujuan yang telah ditentukan.

Motivasi menurut Ranupandojo dan Hasan dalam Abrivanto et al (2014) merupakan proses untuk mencoba mempengaruhi seseorang agar melakukan sesuatu yang kita inginkan. Menurut Hasibuan (2007:141) motivasi adalah hal yang 
menyebabkan, menyalurkan, dan mendukung perilaku manusia, supaya mau bekerja giat dan atusias mencapai hasil yang optimal.

\section{Disiplin Kerja}

MenurutRivai (2004) disiplin kerja adalah suatu alat yang digunakan manajer untuk berkomunikasi dengan karyawan agar mereka bersedia untuk mengubah suatu perilaku serta sebagai suatu upaya untuk meningkatkan kesadaran dan kesediaan seseorang menaati semua peraturan perusahaan dan norma-norma sosial yang berlaku. Hasibuan (2007:193) berpendapat bahwa disiplin kerja adalah kesadaran dan kesediaanseseorang menaati semua peraturan perusahaan dan norma-norma sosial yang berlaku.

Dari beberapa pengertian disiplin kerja yang dikemukakan oleh beberapa ahli dapat disimpulkan bahwa disiplin kerja merupakan suatu sikap, tingkah laku, dan peraturan yangsesuai dengan peraturan baik tertulis ataupun tidak tertulis, dan bila melanggar akan ada sanksi atas pelanggarannya.

\section{Kinerja Karyawan}

Kinerja berasal dari pengertianperformance. Ada pula yang memberikan pengertian performance sebagai hasil kerja atau prestasi kerja. Namun, sebenarnya kinerja mempunyai makna yang lebih luas, bukan hanya hasil kerja, tetapi termasuk proses pekerjaan berlangsung. Dessler (2006) mengatakan bahwa kinerja karyawan merupakan prestasi kerja, yaitu perbandingan antara hasil kerja yang dilihat secara nyata dengan standar kerja yang telah ditetapkan oleh organisasi.

Menurut Mangkunegara (2007) kinerja adalah hasil kerja secara kualitas dan kuantitas yang dicapai oleh seseorang karyawan dalam melaksanakan tugasnya sesuai dengan tanggung jawab yang diberikan kepadanya.Kinerja karyawan dapat diartikan sebagai suatu hasil kerja yang dicapai oleh seseorang dalam melaksanakan tugas-tugas yang dibebankankepadanya yang didasarkan atas kecakapan, pengalaman, kesungguhan dan waktu. (Hasibuan, 2012).

\section{Kerangka Berfikir}

Adapun kerangka penelitian dalam penelitian ini adalah sebagai berikut: 


\section{Gambar 1. Kerangka Berfikir}

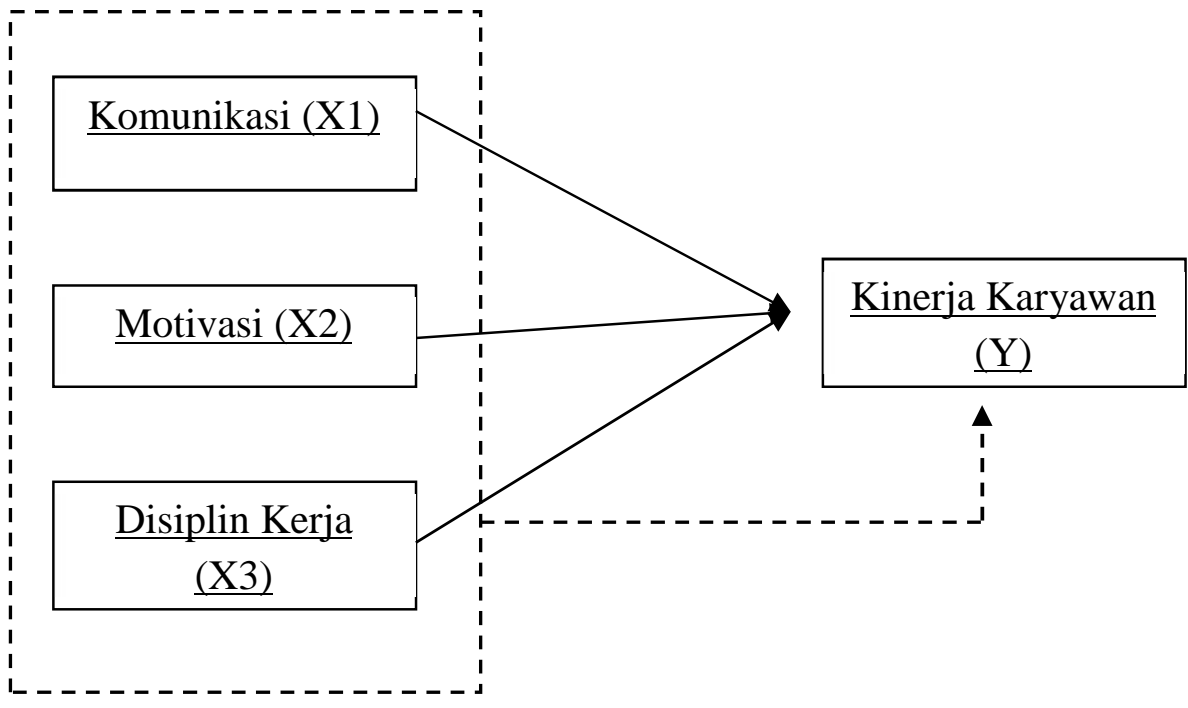

Sumber: Karismadiyanto (2014)

Keterangan :

$\longrightarrow \quad=$ Secara parsial (individu)

$\rightarrow-$ Secara simultan (bersama-sama)

\section{Hipotesis}

Menurut Sugiyono (2016:134), hipotesis merupakan jawaban sementara terhadap rumusan masalah penelitian, dimana rumusan masalah penelitian telah dinyatakan dalam bentuk kalimat pertanyaan. Berdasarkan model hipotesis tersebut, maka dapat dirumuskan hipotesis sebagai berikut:

H1 : Komunikasi berpengaruh positif terhadap kinerja pada karyawan CV. Denov Putra Brilian Tulungagung

H2 : Motivasi berpengaruh positif terhadap kinerja pada karyawan CV. Denov Putra Brilian Tulungagung

H3 : Disiplin kerja berpengaruh positif terhadap kinerja pada karyawan CV. Denov Putra Brilian Tulungagung

H4 : Komunikasi, motivasi, dan disiplin kerja berpengaruh simultan terhadap kinerja karyawan CV. Denov Putra Brilian Tulungagung

\section{METODE PENELITIAN}

\section{Populasi dan Sampel Penelitian}

Populasi menurut Sugiyono (2016:80) adalah wilayah generalisasi yang terdiri dari objek atau subjek yang mempunyai kualitas dan karakteristik tertentu yang ditunjuk 
oleh peneliti untuk dipelajari dan kemudian ditarik kesimpulannya. Populasi dalam penelitian ini adalah semua karyawan CV. Denov Putra Brilian Tulungagung yang berjumlah 63 karyawan.

Sugiyono (2016:81) menyatakan bahwa sampel merupakan bagian dari jumlah dan karakteristik yang dimiliki oleh populasi tersebut. Sampel yang digunakan dalam penelitian ini adalah semua karyawan CV. Denov Putra Brilian Tulungagung.

\section{Variabel penelitian}

Variabel penelitian adalah suatu atribut atau sifat atau nilai dari orang, obyek atau kegiatan yang mempunyai variasi tertentu yang ditetapkan oleh peneliti untuk dipelajari dan kemudian ditarik kesimpulannya (Sugiyono, 2016:39). Penelitian ini menggunakan dua variabel yaitu variabel independen dan variabel dependen.

a. Variabel Terikat (Dependent Variable)

Menurut Sugiyono (2016:39), variabel dependen atau biasa disebut variabel terikat adalah "variabel yang dipengaruhi atau yang menjadi akibat karena adanya variabel bebas". Didalam penelitian yang menjadi variabel terikat adalah kinerja karyawan (Y).

b. Variabel Bebas (Independent Variable)

Menurut Sugiyono (2016:39), variabel independen atau yang biasa disebut variabel bebas adalah "variabel yang mempengaruhi atau yang menjadi sebab perubahan atau timbulnya variabel dependen (terikat). Didalam penelitian yang menjadi variabel bebas adalah

1) Komunikasi (X1)

2) Motivasi (X2)

3) Disiplin Kerja (X3)

\section{Metode Pengumpulan Data}

Metode pengumpulan data yang digunakan dalam penelitian ini adalah dengan cara :

\section{A. Kuisioner}

Angket atau kuisioner adalah teknik pengumpulan data yang dilakukan dengan cara memberi seperangkat pertanyaan atau pernyataan tertulis kepada responden untuk dijawabnya (Sugiyono, 2016:142).

B. Wawancara

Pengumpulan data dengan cara wawancara.

C. Studi Pustaka 
Studi pustaka merupakan metode pengumpulan data yang dilakukan dengan membaca buku-buku, literatur, jurnal-jurnal, referensi yang berkaitan dengan penelitian terdahulu yang berkaitan dengan penelitian yang dilakukan.

\section{Metode Analisis Data}

Analisis data yang digunakan dalam penelitian ini adalah teknik analisis data kuantitatif yaitu suatu analisis yang digunakan melalui suatu pengukuran yang berupa angka-angka dengan menggunakan metode statistik (Sugiyono, 2012). Penelitian ini menggunakan komputer dengan bantuan program SPSS versi 20.0. Tahap analisis data dilakukan sebagai berikut :

\section{Uji Instrumen Penelitian :}

\section{Uji Validitas}

Menurut Sekaran (2006), validitas adalah bukti bahwa instrument, teknik, atau proses yang digunakan untuk mengukur sebuah konsep benar-benar mengukur konsep yang dimaksudkan. Analisis validitas item bertujuan untuk mengukur valid atau tidaknya suatu item pernyataan. Menurut Sugiyono (2016:126) bila koefisien korelasi diatas 0,30 $(\geq 0,30)$, maka butir instrumen dinyatakan valid.

\section{Uji Reliabilitas}

Instrumen yang reliabel adalah instrumen yang bila digunakan beberapa kali untukmengukur obyek yang sama, akan menghasilkan data yang sama (Martinus, 2016). Reliabilitas variabel ditentukan berdasarkan nilaicronbach's alpha, apabila nilaicronbach's alpha >0,6 makadikatakan variabel tersebut reliabel atau dapat diandalkan (Sugiyono, 2011).

\section{Regresi Linier Berganda}

Analisis regresi linier berganda merupakan salah satu analisis yang bertujuan untuk mengetahui pegaruh suatu variabel terhadap variabel lain (Karismadiyanto, 2014). Menurut Prayitno (2010), rumus analisis regresi linier berganda sebagai berikut:

\section{$Y=\alpha+b_{1} X_{1}+b_{2} X_{2}+b_{3} X_{3}+e$}

\section{Pengujian Hipotesis}

Uji hipotesis dalam penelitian ini dilakukan terhadap hipotesis statistik menggunakan uji t dan uji F. 


\section{Uji t}

Uji t digunakan untuk mengetahui pengaruh signifikasi dari tiap-tiap variabel bebas terhadap variabel terikat. Menurut Sugiyono (2008) untuk menarik kesimpulan hipotesis diterima atau ditolaknya adalah dengan membandingkan besarnya nilai $t_{\text {hitung }}$ dan $t_{\text {tabel. }}$

\section{Uji F}

Uji F digunakan untuk mengetahui pengaruh signifikasi dari variabel bebas (X) secara simultan terhadap variabel terikat (Y). Menurut Sugiyono (2008) untuk menarik kesimpulan ada tidaknya pengaruh variabel bebas $(\mathrm{X})$ secara simultan terhadap variabel terikat adalah dengan membandingkan besarnya nilai $\mathrm{F}_{\text {hitung }}$ dan $\mathrm{F}_{\text {tabel. }}$.

\section{HASIL PENELITIAN DAN PEMBAHASAN}

\section{Uji Instrumen Penelitian}

\section{Uji Validitas}

Uji validitas digunakan untuk menguji sejauh mana ketepatan alat pengukur dapat mengungkapkan konsep gejala/kejadian yang diukur. Item kuisioner dinyatakan valid apabila nilai $r$ hitung $>r$ tabel. Pengujian validitas selengkapnya dapat dilihat pada tabel 4.7 sebagai berikut ini:

Tabel 2. Hasil Pengujian Validitas

\begin{tabular}{|l|l|l|l|l|}
\hline No & Variabel/Indikator & r hitung & r tabel & Keterangan \\
\hline $\mathbf{1 .}$ & Komunikasi (X1) & & & \\
& Indikator 1 & 0,724 & 0,248 & Valid \\
& Indikator 2 & 0,627 & 0,248 & Valid \\
& Indikator 3 & 0,662 & 0,248 & Valid \\
& Indikator 4 & 0,603 & 0,248 & Valid \\
\hline 2. & Motivasi (X2) & & & \\
& Indikator 1 & 0,711 & 0,248 & Valid \\
& Indikator 2 & 0,512 & 0,248 & Valid \\
& Indikator 3 & 0,595 & 0,248 & Valid \\
& Indikator 4 & 0,684 & 0,248 & Valid \\
& Indikator 5 & 0,599 & 0,248 & Valid \\
& & & & \\
\hline 3. & Disiplin Kerja (X3) & \multirow{2}{*}{0,648} & 0,248 & Valid \\
& Indikator 1 & 0,630 & 0,248 & Valid \\
& Indikator 2 & 0,519 & 0,248 & Valid \\
& Indikator 3 & 0,519 & 0,248 & Valid \\
& Indikator 4 & 0,528 & 0,248 & Valid \\
& Indikator 5 & & & \\
\hline
\end{tabular}




\begin{tabular}{|l|l|l|l|l|}
\hline 4. & Kinerja Karyawan (Y) & & & \\
& Indikator 1 & 0,530 & 0,248 & Valid \\
& Indikator 2 & 0,544 & 0,248 & Valid \\
& Indikator 3 & 0,636 & 0,248 & Valid \\
& Indikator 4 & 0,714 & 0,248 & Valid \\
& Indikator 5 & 0,684 & 0,248 & Valid \\
& Indikator 6 & 0,865 & 0,248 & Valid \\
& Indikator 7 & 0,714 & 0,248 & Valid \\
\hline
\end{tabular}

Sumber : Data primer yang diolah (2018)

Tabel 4.7 terlihat bahwa korelasi antara masing-masing indicator terhadap total konsep skor dari setiap variabel menunjukkan hasil yang signifikan dan menunjukkan bahwa $r$ hitung $>0,248$. Sehingga dapat disimpulkan bahwa semua item pertanyaan dinyatakan valid dan dapat digunakan untuk penelitian berikutnya.

\section{Uji Reliabilitas}

Uji reliabilitas digunakan untuk menguji sejauh mana kepercayaan suatu alat pengukur untuk dapat digunakan lagi untuk penelitian yang sama. Pengujian reliabilitas dalam penelitian ini dengan menggunakan Cronbach's Alpha. Hasil pengujian reliabilitas untuk masing-masing variabel yang diringkas pada tabel 4.8 berikut ini :

Tabel 3. Hasil Pengujian Reliabilitas

\begin{tabular}{|l|c|c|}
\hline Variabel & Cronbad'sAlpha & Keterangan \\
\hline Komunikasi (X1) & 0,650 & Reliabel \\
Motivasi (X2) & 0,601 & Reliabel \\
Disiplin Kerja (X3) & 0,679 & Reliabel \\
Kinerja Karyawan (Y) & 0,799 & Reliabel \\
\hline
\end{tabular}

Sumber : Data primer yang diolah (2018)

Berdasarkan hasil uji reliabilitas tersebut menunjukkan bahwa semua variabel mempunyai Cronbach's Alpha lebih dari 0,6 sehingga dapat dikatakan konsep pengukuran masing-masing variabel dari kuisioner adalah reliabel dan layak digunakan sebagai alat ukur. 


\section{Analisis Regresi Berganda}

Tabel 4. HasilAnalisis Regresi Berganda

Coefficients $^{\mathbf{a}}$

\begin{tabular}{|ll|ll|l|}
\hline \multirow{2}{*}{ Model } & \multicolumn{2}{|l|}{ Unstandardized Coefficients } & $\begin{array}{l}\text { Standardized } \\
\text { Coefficients }\end{array}$ \\
\cline { 2 - 4 } & B & Std. Error & Beta \\
\hline \multirow{4}{*}{1 (Constant) } &, 947 & 1,977 & \\
& Komunikasi &, 455 &, 214 &, 241 \\
& Motivasi &, 553 &, 124 &, 405 \\
& Disiplin &, 495 &, 169 &, 326 \\
\hline
\end{tabular}

a. Dependent Variable: Kinerja Karyawan

Sumber: Hasil olah output SPSS (2018)

Berdasarkan tabel 4 di atas maka dapat ditentukan persamaan regresi berganda sebagai berikut :

$$
\mathrm{Y}=0,947+0,455 \mathrm{X} 1+0,553 \mathrm{X} 2+0,495 \mathrm{X3}+\mathrm{e}
$$

\section{Pengujian Hipotesis}

Uji t

Tabel 5. Hasil Uji t

Coefficients $^{\mathrm{a}}$

\begin{tabular}{|c|c|c|c|c|c|c|}
\hline \multirow{2}{*}{\multicolumn{2}{|c|}{ Model }} & \multicolumn{2}{|c|}{$\begin{array}{l}\text { Unstandardized } \\
\text { Coefficients }\end{array}$} & $\begin{array}{l}\text { Standardized } \\
\text { Coefficients }\end{array}$ & \multirow[t]{2}{*}{$\mathrm{T}$} & \multirow[t]{2}{*}{ Sig. } \\
\hline & & $\mathrm{B}$ & Std. Error & Beta & & \\
\hline \multirow{4}{*}{1} & (Constant) &, 947 & 1,977 & & 479 & ,634 \\
\hline & Komunikasi &, 455 &, 214 &, 241 & 2,130 & ,037 \\
\hline & Motivasi &, 553 &, 124 &, 405 & 4,469 & ,000 \\
\hline & $\begin{array}{l}\text { Disiplin } \\
\text { Kerja }\end{array}$ &, 495 & ,169 &, 326 & 2,935 & ,005 \\
\hline
\end{tabular}

a. Dependent Variable: Kinerja Karyawan

Sumber : Data hasil olah SPSS (2018)

Berdasarkan hasil regresi pada tabel 5 di atas menunjukkan bahwa:

H1 : Hasil pengujian hipotesis komunikasi menunjukkan nilai t hitung sebesar 2,130 dengan taraf signifikasi yaitu $0,037<0,05$ yang berarti bahwa hipotesis dalam penelitian ini, Ho ditolak dan Ha diterima. Dengan demikian, variabel komunikasi secara parsial berpengaruh positif dan signifikan terhadap kinerja karyawan CV. Denov Putra Brilian Tulungagung. 
H2 : Hasil pengujian hipotesis motivasi menunjukkan nilai thitung sebesar 4,469 dengan taraf signifikasi yaitu $0,000<0,05$ yang berarti bahwa hipotesis dalam penelitian ini, Ho ditolak dan Ha diterima. Dengan demikian, variabel motivasi secara parsial berpengaruh positif dan signifikan terhadap kinerja karyawan CV. Denov Putra Brilian Tulungagung.

H3 : Hasil pengujian hipotesis disiplin kerja menunjukkan nilai t hitung sebesar 2,935 dengan taraf signifikasi yaitu $0,005<0,05$ yang berarti bahwa hipotesis dalam penelitian ini, Ho ditolak dan Ha diterima. Dengan demikian, variabel disiplin kerja secara parsial berpengaruh positif dan signifikan terhadap kinerja karyawan $\mathrm{CV}$. Denov Putra Brilian Tulungagung.

\section{Uji F}

Tabel 6. Hasil Uji F

ANOVA $^{\mathrm{a}}$

\begin{tabular}{|c|c|c|c|c|c|}
\hline Model & $\begin{array}{l}\text { Sum of } \\
\text { Squares }\end{array}$ & Df & Mean Square & $\mathrm{F}$ & Sig. \\
\hline $\begin{array}{ll} & \text { Regression } \\
1 & \text { Residual } \\
& \text { Total }\end{array}$ & $\begin{array}{l}398,908 \\
113,949 \\
512,857\end{array}$ & $\begin{array}{l}3 \\
59 \\
62\end{array}$ & $\begin{array}{l}132,969 \\
1,931\end{array}$ & 68,848 &, $000^{\mathrm{b}}$ \\
\hline
\end{tabular}

a. Dependent Variable: Kinerja Karyawan

b. Predictors: (Constant), Disiplin Kerja, Motivasi, Komunikasi

Sumber : Data hasil olah SPSS (2018)

Pengujian pengaruh variabel bebas secara bersama-sama terhadap variabel terikat dilakukan dengan menggunakan uji F. Hasil perhitungan statistik menunjukkan nilai F hitung 68,848. Dengan menggunakan batas signifikasi 0,05, maka diperoleh nilai signifikasi 0,000 lebih kecil dari 0,05. Hal ini berarti hipotesis yang menyatakan bahwa secara simultan variabel komunikasi, motivasi, dan disiplin kerja mempunyai pengaruh terhadap kinerja karyawan.

\section{Pembahasan}

\section{Pengaruh Komunikasi terhadap Kinerja Karyawan}

Berdasarkan hasil uji thitung sebesar 2,130 signifikan pada 0,037. Sedangkan t tabel adalah sebesar 2,001 yang berarti t hitung > t tabel dan nilai signifikan komunikasi sebesar 0,037<0,05 yang artinya H0 ditolak dan H1 diterima. Dengan demikian terbukti bahwa komunikasi (X1) secara parsial atau individu berpengaruh positif dan signifikan terhadap kinerja karyawan (Y). Artinya bahwa ada pengaruh yang positif dan signifikan 
antara variabel komunikasiterhadap kinerja karyawan di CV. Denov Putra Brilian Tulungagung.

\section{Pengaruh Motivasi terhadap Kinerja Karyawan}

Berdasarkan hasil uji thitung sebesar 4,469 signifikan pada 0,000. Sedangkan t tabel adalah sebesar 2,001 yang berarti $t$ hitung $>t$ tabel dan nilai signifikan motivasi sebesar 0,000 < 0,05 yang artinya H0 ditolak dan H1 diterima. Dengan demikian terbukti bahwa motivasi (X2) secara parsial atau individu berpengaruh positif dan signifikan terhadap kinerja karyawan (Y). Artinya bahwa ada pengaruh yang positif dan signifikan antara variabel motivasiterhadap kinerja karyawan di CV. Denov Putra Brilian Tulungagung. Hal tersebut sesuai dengan penelitian terdahulu (Rahayu \& Ruhamak, 2018)

\section{Pengaruh Disiplin Kerjaterhadap Kinerja Karyawan}

Berdasarkan hasil uji thitung sebesar 2,935 signifikan pada 0,005. Sedangkan t tabel adalah sebesar 2,001 yang berarti thitung $>\mathrm{t}$ tabel dan nilai signifikan disiplin kerja sebesar 0,005 < 0,05 yang artinya H0 ditolak dan H1 diterima. Dengan demikian terbukti bahwa disiplin kerja (X3) secara parsial atau individu berpengaruh positif dan signifikan terhadap kinerja karyawan (Y). Artinya bahwa ada pengaruh yang positif dan signifikan antara variabel disiplin kerjaterhadap kinerja karyawan di CV. Denov Putra Brilian Tulungagung. Hal tersebut sesuai dengan penelitian terdahulu (Yunanto, 2018)

\section{Pengaruh Komunikasi, Motivasi, Disiplin Kerjaterhadap Kinerja Karyawan}

Berdasarkan hasil uji $\mathrm{F}$ hitung memperoleh nilai $\mathrm{F}$ hitung sebesar 68,848 signifikan pada 0,000 sedangkan $\mathrm{F}$ tabel adalah sebesar 2,76. F Hitung $>\mathrm{F}$ tabel dan signifikasi 0,000 < 0,05 dinyatakan $\mathrm{H} 0$ ditolak dan Ha diterima yang berarti ada pengaruh bersama-sama dan signifikan antara variabel komunikasi, motivasi, disiplin kerja terhadap kinerja karyawan. Hasil penelitian ini sejalan dengan penelitian yang dilakukan oleh Agung Karismadiyanto (2014), Windy Dyah Indryani (2016), dan Lung Mang Indah Mariani (2017) yang menyatakan bahwa adanya pengaruh secara simultan antara variabel komunikasi, motivasi, disiplin kerja terhadap kinerja karyawan CV. Denov Putra Brilian Tulugagung. Dalam penelitian ini diketahui adanya pengaruh yang simultan antara komunikasi (X1), motivasi (X2), dan disiplin kerja (X3) terhadap kinerja karyawan (Y).

\section{KESIMPULAN DAN SARAN}

\section{Kesimpulan}


Pengujian membuktikan bahwa komunikasi berpengaruh positif dan signifikan terhadap kinerja karyawan. Dilihat dari perhitungan, $\mathrm{t}$ hitung lebih besar dari t tabel dan signifikansi kurang dari 0,05.

1. Pengujian membuktikan bahwa motivasi berpengaruh positif dan signifikan terhadap kinerja karyawan. Dilihat dari perhitungan, t hitung lebih besar dari t tabel dan signifikansi kurang dari 0,05.

2. Pengujian membuktikan bahwa disiplin kerja berpengaruh positif dan signifikan terhadap kinerja karyawan. Dilihat dari perhitungan, $\mathrm{t}$ hitung lebih besar dari $\mathrm{t}$ tabel dan signifikansi kurang dari 0,05.

3. Pengujian membuktikan bahwa komunikasi, motivasi, dan disiplin kerja berpengaruh secara simultan terhadap kinerja karyawan. Dilihat dari perhitungan, F hitung lebih besar dari $\mathrm{F}$ tabel dan signifikansi kurang dari 0,05.

\section{Saran}

1. Bagi perusahaan

Sebaiknya perusahaan dalam meningkatkan kinerja karyawan lebih menitik beratkan pada motivasi karyawaan, berdasarkan dari kuisioner yang telah diisi oleh karyawan CV. Denov Putra Brilian Tulungagung diperoleh data bahwa karyawan memiliki motivasi yang tinggi pada pekerjaan yang mereka laksanakan, sehingga dengan perusahaan lebih memotivasi karyawannya misalnya dengan memberikan penghargaan terhadap karyawan yang berprestasi atau kenaikan jabatan akan dapat meningkatkan kinerja karyawan yang lebih baik lagi.

2. Bagi peneliti selanjutnya

Masih ada variabel-variabel lain yang harus diperhatikan dalam penelitian ini. Penelitian-penelitian lebih lanjut, sebaiknya menambah variabel lain yang dapat mempengaruhi kinerja karyawan, karena dengan semakin baik kinerja dari karyawan makan akan bepengaruh baik juga bagi perusahaan

\section{DAFTAR PUSTAKA}

Abdullah, M. 2014. Manajemen dan Evaluasi Kinerja Karyawan. Penerbit Aswaja Pressindo, Yogyakarta.

Abrivianto, O., B. Swasta, dan H. N Utami. 2014. Pengaruh Motivasi Kerja Dan Komitmen Organisasional Terhadap Kinerja Karyawan (Studi pada karyawan bagian HRD PT. Arthawena Sakti Gemilang Malang). Jurnal Administrasi Bisnis. Vol. 7(2). 
Anteyenia. 2015. Pengaruh Komunikasi, Motivasi Dan Disiplin Kerja Terhadap Kinerja Pegawai Pegadaian Cabang Kediri Tahun 2015. Universitas Nusantara Pgri Kediri. Skripsi.

Agus Syaiful Amrhy. 2014. Pengaruh Komunikasi Yang Efektif, Motivasi Kerja Dan Disiplin Kerja Terhadap Kinerja Karyawan.

Danish, Qaiser Rizwan dan Ali, Usman. 2010. Impact of Reward and Recognition on Job Satisfaction and Motivation : An Empirical Study From Pakistan. International Journal of Business and Management, 5(2): 159-167.

Rahayu, B., \& Ruhamak, M. D. (2018). Pengaruh Kepemimpinan, Insentif, Remunerasi Dan Motivasi Terhadap Kinerja Karyawan (Studi Kasus Pada Pt Industri Sandang Pangan Nusantara Cilacap). Ekonika : Jurnal Ekonomi Universitas Kadiri, 2(1), 1 22. https://doi.org/10.30737/ekonika.v2i1.15

Satriyono, G. (2017). ANALISIS KEMAMPUAN KEPEMIMPINAN TERHADAP KINERJA DOSEN PADA UNIVERSITAS KADIRI. JURNAL EKOMAKS, 6(1).

Yunanto, Y. (2018). Analisis Pengaruh Kualitas Pelayanan Dan Disiplin Kerja Karyawan Terhadap Kepuasan Pasien Askes Di PT ASKES Kediri. Ekonika : Jurnal Ekonomi Universitas Kadiri, 1(1), 26-37. https://doi.org/10.30737/ekonika.v1i1.3

Dessler, G. 2006. Manajemen Sumber Daya Manusia Jilid 1. PT Indeks, Jakarta.

Gupta, Atul dan Sharon, R. Muita. 2013. Relationship between Entrepreneurial Personality, Performance, Job Satisfaction and Operations Strategy: An Empirical Examination. International Journal Of Business and Management, 8(2): 387-393.

Harlie, M. 2010. Pengaruh Disiplin Kerja, Motivasi dan Pengembangan Karier terhadap Kinerja pegawai negeri sipil pada pemerintahan kabupaten Tabalong di Tanjung Kalimantan Selatan. Jurnal Manajemen dan Akuntansi. 11 (2): 860-867.

Hasibuan. 2007. Manajemen Sumber Daya Manusia. PT. Bumi Aksara, Jakarta. Melayu. 2010. Manajemen Sumber Daya Manusia. Edisi Revisi. Bumi Aksara, Jakarta.

Herujito.2001. Dasar-Dasar Manajemen. PT Grasindo, Jakarta.

Ika, Agustina. 2009. Faktor-faktor Motivasi yang mempengaruhi Kinerja Karyawan pada PT.Gaya Manunggal Kresitama. Jurnal Aplikasi Ekonomi, 2(5): 64-76.

Indryani dan Budiarti. 2016. Pengaruh Gaya Kepemimpinan Motivasi Dan Disiplin Kerja Terhadap Kinerja Karyawan. Jurnal Ilmu dan Riset Manajemen : Volume 5, Nomor 9, September 2016 ISSN : 2461-0593

Iriani. 2010. Manajemen Sumber Daya Manusia. Edisi. Bumi Aksara, Jakarta.

Karismadiyanto.2014. Analisis Pengaruh Motivasi Kerja, Disiplin Kerja Dan Komunikasi Terhadap Kinerja Karyawan. Jurnal Ekonomi dan Bisnis, 2014.

Kiswanto, M. 2010. Pengaruh Kepemimpinan dan Komunikasi Terhadap Kinerja Karyawan Kaltim Pos Samarinda. Jurnal Eksis, 6(1): 1267-1439.

Mangkunegara, Anwar Prabu. 2012. Evaluasi Kinerja Sumber Daya Manusia. Bandung: PT. Refika Aditama.

.2010. Evaluasi Kinerja Sumber Daya Manusia.Cetakan kelima. PT. Refika Aditama, Bandung.

Martinus Dan Budiyanto. 2016. Pengaruh Kompensasi Dan Motivasi Kerja Terhadap Kinerja Karyawan Pada Pt. Devina Surabaya.Jurnal Ilmu Dan Riset Manajemen : Volume 5, Nomor 1, Januari 2016 ISSN : 2461-0593 
Paripurna, I Gede Diatmika. 2012. Pengaruh Kepemimpinan, Lingkungan Kerja Dan Komunikasi Terhadap Kepuasan Kerja Karyawan. Jurnal Manajemen, 2(1): 582589.

Rivai, veithzal. 2004. Menejemen Sumber Daya Manusia untuk Perusahaan : Dari Teori ke Praktik. PT Raja Grafindo Persada, Jakarta.

Sariyathi dan Mariani.2017. Pengaruh Motivasi, Komunikasi Dan Disiplin Kerja Terhadap Kinerja Karyawan Warung Mina Peguyangan Di Denpasar. E-Jurnal Manajemen Unud, Vol. 6, No. 7, 2017: 3540-3569 ISSN : 2302-8912

Sarjono. 2011. SPSS vs LISREL Sebuah Pengantar Aplikasi untuk Riset. Salemba Empat, Jakarta.

Siagian. 2003. Manajemen Sumber Daya Manusia. Bumi Aksara, Jakarta.

Sudarmo.Pengaruh Gaya Kepemimpinan, Motivasi, Dan Disiplin Kerja TerhadapKinerja Karyawan PT. Empat Enam Jaya Abadi Balikpapan. Jurnal Sains Terapan No. 1 Vol. 2 Juni ISSN $2406-8810$

Sugiyono. 2016. Metode Penelitian Kuantitatif, Kualitatif, dan R\&D. Bandung:Alfabeta

Sutrisno, E. 2009. Manajemen Sumber Daya Manusia. Edisi Pertama, Cetakan Pertama. Kencana, Jakarta.

Turangan, Reynold Briando., Sifrid, S. Pangemanan., dan Maria, V. J. Tielung. 2016. Employee Performance Analysis Through Leadership Style, Motivation \& Work Discipline At Waroeng Charity Manado. Jurnal Emba. 4(1): 1068-1076. 